\title{
Segmental Liver Stiffness Evaluated with Magnetic Resonance Elastography Is Responsive to Endovascular Intervention in Patients with Budd-Chiari Syndrome
}

\author{
Peng Xu, MD ${ }^{1 *}$, Lulu Lyu, MD ${ }^{2,3 *}$, Haitao Ge, PhD ${ }^{1}$, Muhammad Umair Sami, MD ${ }^{1}$, Panpan Liu, MD ${ }^{1}$, \\ Chunfeng $\mathrm{Hu}, \mathrm{MD}^{1}$, Kai $\mathrm{Xu}, \mathrm{MD}^{1,3}$ \\ ${ }^{1}$ Department of Radiology, Affiliated Hospital of Xuzhou Medical University, Xuzhou, China; ${ }^{2}$ Department of CT and MRI, Xuzhou Central Hospital, \\ Xuzhou, China; ${ }^{3}$ The First School of Clinical Medicine, Nanjing Medical University, Nanjing, China
}

Objective: To assess segmental liver stiffness (LS) with MRI before and after endovascular intervention in patients with Budd-Chiari syndrome (BCS).

Materials and Methods: Twenty-three patients (13 males and 10 females; mean age, $42.6 \pm 12.6$ years; age range, 31-56 years) with BCS as a primary liver disease were recruited for this study. Two consecutive magnetic resonance elastography (MRE) examinations were performed before the endovascular treatment. Fifteen patients who underwent endovascular intervention treatment also had follow-up MRE scans within three days after the procedure. LS was measured in three liver segments: the right posterior, right anterior, and left medial segments. Inter-reader and inter-exam repeatability were analyzed with intraclass correlation coefficients (ICCs) and Bland-Altman analysis. Segmental LS and clinical characteristics before and after the intervention were also compared.

Results: Within three days of the endovascular intervention, all three segmental LS values decreased: LS of the right posterior segment $=7.23 \pm 0.88 \mathrm{kPa}$ (before) vs. $4.94 \pm 0.84 \mathrm{kPa}$ (after), LS of the right anterior segment $=7.30 \pm 1.06 \mathrm{kPa}$ (before) vs. $4.77 \pm 0.85 \mathrm{kPa}$ (after), and LS of the left medial segment $=7.22 \pm 0.87 \mathrm{kPa}$ (before) vs. $4.87 \pm 0.72 \mathrm{kPa}$ (after) (all $p=0.001$ ). There was a significant correlation between LS changes and venous pressure gradient changes before and after treatments $(r=0.651, p=0.009)$. The clinical manifestations of all 15 patients significantly improved after therapy. The MRE repeatability was excellent, with insignificant variations (inter-reader, ICC $=0.839-0.943$ : inter-examination, ICC $=0.765-0.869$ ). BlandAltman analysis confirmed excellent agreement (limits of agreement, 13.4-19.4\%).

Conclusion: Segmental LS measured by MRE is a promising repeatable quantitative biomarker for monitoring the treatment response to minimally invasive endovascular intervention in patients with BCS.

Keywords: Budd-Chiari syndrome; Magnetic resonance elastography; Liver stiffness; Endovascular treatment

\section{INTRODUCTION}

Primary Budd-Chiari syndrome (BCS) is a rare disorder caused by obstruction of the hepatic venous outflow tract (1), resulting in elevated hepatic congestion, portal hypertension, and possible cirrhosis and increased liver stiffness (LS) $(2,3)$. LS can be assessed by elastographic techniques such as transient elastography (TE) and magnetic resonance elastography (MRE) (3-6). A previous study showed that TE is a useful noninvasive tool for evaluating

Received November 9, 2018; accepted after revision January 18, 2019.

This study was supported by Clinical Medical Science and Technology Project of Jiangsu Province (grant number: BE2017637) and Medical Innovation Team of Jiangsu Province (grant number: CXTDA2017028).

*These authors contributed equally to this work.

Corresponding author: Kai Xu, MD, Department of Radiology, Affiliated Hospital of Xuzhou Medical University, 99 Huaihai West Road, Xuzhou 221002, China.

- Tel: (86) 13952205532•Fax: (86) 051685807093 •E-mail: xuk_xuzhou@126.com

This is an 0pen Access article distributed under the terms of the Creative Commons Attribution Non-Commercial License (https:// creativecommons.org/licenses/by-nc/4.0) which permits unrestricted non-commercial use, distribution, and reproduction in any medium, provided the original work is properly cited. 
hepatic congestion and it provides indirect insights into the outcomes and benefits of interventional therapy in patients with BCS (7). However, TE has significant limitations. There are no real-time or gray-scale imaging options and it is difficult to measure LS values in obese patients and patients with ascites (5).

In recent years, MRE has proved to be a promising diagnostic tool with high reproducibility and repeatability for assessing LS and fibrosis (8-10). However, most studies have only assessed patients with fibrosis caused by hepatitis and non-alcoholic fatty liver (11). The main aim of this study was to measure LS using MRE in patients with BCS and to assess the usefulness of measuring LS to evaluate endovascular intervention outcomes.

\section{MATERIALS AND METHODS}

This prospective clinical study was approved by the local Institutional Review Board. Written informed consent was obtained from all patients.

\section{Subjects}

Between December 2016 and August 2018, a total of 28 patients were identified with suspected BCS based on clinical and radiologic examinations. Magnetic resonance imaging (MRI) and magnetic resonance venous angiography were performed in all 28 patients. Only patients who had primary BCS and had no liver tumor were included in the final analysis. Among the 28 patients, 23 fulfilled these criteria. These patients comprised of 13 males and 10 females with a mean age of $42.6 \pm 12.6$ years (range $31-56$ years), and a mean body mass index of $21.3 \mathrm{~kg} / \mathrm{m}^{2}$ (range $17.3-23.7 \mathrm{~kg} / \mathrm{m}^{2}$ ).

\section{MRE and Endovascular Intervention}

All MRE examinations were performed with a 3T clinical unit (Discovery 750w, GE Healthcare, Milwaukee, WI, USA) equipped with a 32-element phased-array coil. A 19-cmdiameter, $1.5-\mathrm{cm}$-thick passive pneumatic driver was placed over the right rib cage at the level of the xiphoid process to generate $60-\mathrm{Hz}$ shear waves. Magnitude and unwrapped phase difference wave images were acquired with a twodimensional spin-echo echo-planar MRE sequence using the following parameters: repetition time/echo time $=1000 / 59$ ms, matrix: $64 \times 64,8-\mathrm{mm}$ thickness with no gap, and 42-cm field-of-view (12). Four transverse slices through the largest transverse dimension (including the three main hepatic veins
[HVs]) of the liver were obtained during a 24-second breathhold at the end of expiration. All patients underwent two MRE examinations before the interventional treatment started. When the first examination was completed, the patient was repositioned before the second scan was performed.

For patients who had undergone only balloon dilation, a third MRE examination was performed within three days after the interventional therapy. The inferior vena cava (IVC) balloon had a diameter of 26-30 mm and a length of 40-50 mm (Optimed, Ettlingen, Germany; or Cook Medical, Bloomington, IN, USA). The HV balloon had a diameter of 10-14 $\mathrm{mm}$ and a length of $40 \mathrm{~mm}$ (Cook Medical). The pressure gradient between either the HV or IVC and the right atrium was measured through catheterization before and after angioplasty.

Patients were followed-up one month after treatment, and clinical presentation and laboratory variables were recorded.

\section{Quantitative MRE Analysis}

MRE wave images, elastograms, and confidence maps were automatically generated on the scanner. Two radiologists (one with seven years of experience in abdominal MRI and the other with four years of experience) reviewed the MRE images separately; they were blinded to each other's analyses and the treatment information. A central liver section slice including three main HVs and most of the liver parenchyma was selected for LS analysis. Regions of interest (ROIs) were drawn on each of the three liver segments (the right posterior, right anterior, and left medial segments). The method was designed to allow the placement of an ROI as large as possible with free-hand drawing on the anatomical and wave images. ROIs included the greatest part of the liver parenchyma in each segment, excluding large blood vessels (Fig. 1). The average LS values of 15 patients who were treated with balloon therapy were recorded before and after interventional treatment (LS value $=[$ Reader 1 first + Reader 2 first + Reader 1 second + Reader 2 second] / 4).

\section{Statistical Analysis}

All statistical analyses were performed using statistical software (SPSS, v. 20.0, IBM Corp., Armonk, NY; GraphPad Prism 5.0, GraphPad Software, Inc., La Jolla, CA, USA).

The $L S$ values in the three measured segments obtained in the first and second MRE acquisitions were compared using Wilcoxon signed-rank tests. MRE reproducibility was evaluated using the intraclass correlation coefficient (ICC) 
and $95 \%$ Bland-Altman limits of agreement. Agreement between the two readers was assessed using ICCs for each measured segment and each acquisition. An ICC $>0.75$ was considered to represent excellent agreement.

Wilcoxon signed-rank tests and Fisher's exact tests were used to compare BCS patients before and after endovascular intervention. The correlation between changes in LS and pressure gradient values before and after treatment was analyzed using Pearson correlation analysis. For all analyses, $p<0.05$ was considered significant.

\section{RESULTS}

The three segmental LS values of the 23 included study patients ranged from $5.2 \mathrm{kPa}$ to $10.9 \mathrm{kPa}$, with a mean of $7.39 \pm 1.03 \mathrm{kPa}$. The LS values obtained in the first and second acquisitions are summarized in Table 1 . The mean

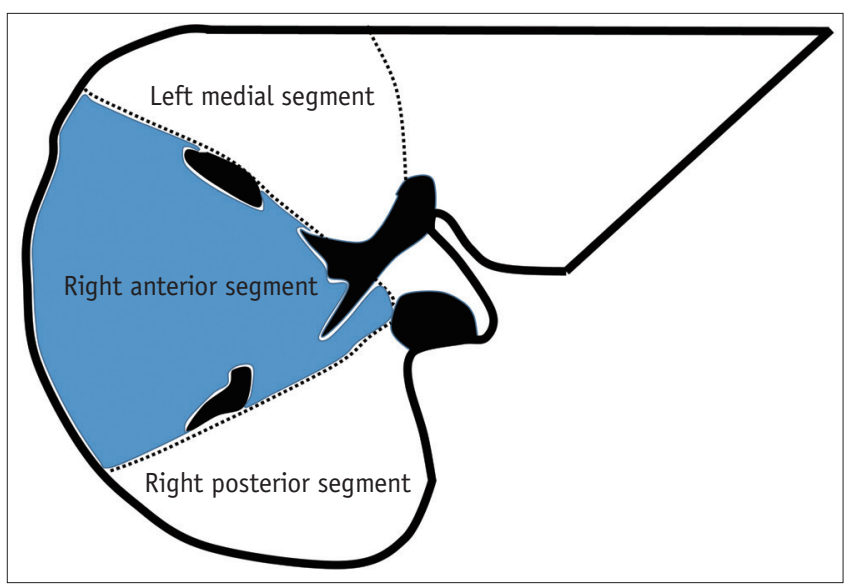

Fig. 1. Three liver segments of interest. ROIs include majority of liver parenchyma in each segment, excluding large blood vessels. ROIs = regions of interest
LS values of the 23 patients obtained by the readers before treatment were not significantly different between the two acquisitions for any of the three different segments ( $p=$ $0.241-0.660$ ). The agreement for LS measurements between the first and second acquisitions was excellent for all three hepatic segments (ICCs $=0.765-0.869$ ) (Fig. 2). The 95\% Bland-Altman limits of agreement ranged from $13.4 \%$ to $19.4 \%$ (Fig. 3). Inter-reader agreement for LS values was excellent in all measured acquisitions and segments (ICCs = 0.839-0.943) (Table 2).

Fifteen patients $(65.2 \%)$ underwent balloon dilation therapy. Eight patients (34.8\%) with stents did not undergo MRE after treatment to prevent the radiofrequency from heating the stent and to avoid imaging artifacts due to stent susceptibility. Among the 15 subjects who underwent balloon dilation therapy, the post-procedural mean LS values were lower than the pre-procedural values for all three hepatic segments: LS of the right posterior segment $=7.23 \pm 0.88 \mathrm{kPa}$ (before) vs. $4.94 \pm 0.84 \mathrm{kPa}$ (after), LS of the right anterior segment $=7.30 \pm 1.06 \mathrm{kPa}$ (before) vs. $4.77 \pm 0.85 \mathrm{kPa}$ (after), and LS of the left medial segment $=7.22 \pm 0.87 \mathrm{kPa}$ (before) vs. $4.87 \pm 0.72 \mathrm{kPa}$ (after) (all $p=0.001$ ) (Table 3$)$. The changes in LS values were statistically significant $(p<0.05)$ (Figs. 4,5$)$. There was also a correlation between changes in the $L S$ and pressure gradient before and after treatment $(r=0.651, p=0.009)$. The clinical manifestations of all 15 patients significantly improved after therapy (Table 4).

\section{DISCUSSION}

Previous studies have demonstrated that MRE is a useful

Table 1. Distributions of LS Values between First and Second Acquisitions $(n=23)$

\begin{tabular}{|c|c|c|c|c|c|c|c|c|c|c|}
\hline \multirow{2}{*}{$\begin{array}{c}\text { Liver } \\
\text { Segments }\end{array}$} & \multicolumn{5}{|c|}{ Reader 1} & \multicolumn{5}{|c|}{ Reader 2} \\
\hline & $\begin{array}{c}\text { First } \\
\text { Acquisition }\end{array}$ & $\begin{array}{c}\text { Second } \\
\text { Acquisition }\end{array}$ & $P$ & $\begin{array}{c}\text { ICC } \\
(95 \% \text { CI })\end{array}$ & $\begin{array}{l}95 \% \text { Limits of } \\
\text { Agreement, \% }\end{array}$ & $\begin{array}{c}\text { First } \\
\text { Acquisition }\end{array}$ & $\begin{array}{c}\text { Second } \\
\text { Acquisition }\end{array}$ & $P$ & $\begin{array}{c}\text { ICC } \\
(95 \% \text { CI })\end{array}$ & $\begin{array}{l}95 \% \text { Limits of } \\
\text { Agreement, } \%\end{array}$ \\
\hline $\begin{array}{l}\text { Right posterior } \\
\text { segment ROI } \\
(\mathrm{kPa})\end{array}$ & $\begin{array}{c}7.23 \pm 0.89 \\
(5.9-9.2)\end{array}$ & $\begin{array}{l}7.30 \pm 1.07 \\
(6.1-10.2)\end{array}$ & 0.591 & $\begin{array}{c}0.840 \\
(0.661-0.929)\end{array}$ & $\begin{array}{c}13.4 \\
(-14.1 ; 12.7)\end{array}$ & $\begin{array}{c}7.36 \pm 1.05 \\
(5.8-9.3)\end{array}$ & $\begin{array}{c}7.50 \pm 1.23 \\
(6.1-10.6)\end{array}$ & 0.269 & $\begin{array}{c}0.860 \\
(0.698-0.938)\end{array}$ & $\begin{array}{c}14.8 \\
(-16.4 ; 13.2)\end{array}$ \\
\hline $\begin{array}{l}\text { Right anterior } \\
\text { segment ROI } \\
(\mathrm{kPa})\end{array}$ & $\begin{array}{c}7.37 \pm 1.10 \\
(5.6-9.8)\end{array}$ & $\begin{array}{c}7.38 \pm 1.22 \\
(5.7-10.9)\end{array}$ & 0.660 & $\begin{array}{c}0.765 \\
(0.522-0.893)\end{array}$ & $\begin{array}{c}19.4 \\
(-19.3 ; 19.4)\end{array}$ & $\begin{array}{c}7.54 \pm 1.20 \\
(5.6-10.1)\end{array}$ & $\begin{array}{c}7.46 \pm 1.28 \\
(5.6-10.7)\end{array}$ & 0.338 & $\begin{array}{c}0.869 \\
(0.717-0.942)\end{array}$ & $\begin{array}{c}16.0 \\
(-14.7 ; 17.2)\end{array}$ \\
\hline $\begin{array}{l}\text { Left medial } \\
\text { segment ROI } \\
(\mathrm{kPa})\end{array}$ & $\begin{array}{c}7.27 \pm 1.13 \\
(5.4-10.7)\end{array}$ & $\begin{array}{c}7.38 \pm 1.19 \\
(5.4-10.3)\end{array}$ & 0.394 & $\begin{array}{c}0.801 \\
(0.587-0.911)\end{array}$ & $\begin{array}{c}16.9 \\
(-18.2 ; 15.5)\end{array}$ & $\begin{array}{c}7.39 \pm 1.10 \\
(5.2-10.3)\end{array}$ & $\begin{array}{c}7.54 \pm 1.25 \\
(5.8-10.4)\end{array}$ & 0.241 & $\begin{array}{c}0.785 \\
(0.558-0.903)\end{array}$ & $\begin{array}{c}17.9 \\
(-19.7 ; 16.0)\end{array}$ \\
\hline
\end{tabular}

$\mathrm{LS}$ values are presented as mean \pm standard deviation (range). $p$ values were calculated using Wilcoxon signed-rank tests. $95 \%$ limits agreement, $\%$ : Bland-Altman analysis. CI = confidence interval, ICC $=$ intraclass correlation coefficient, $\mathrm{LS}=$ liver stiffness, ROI $=$ region of interest 

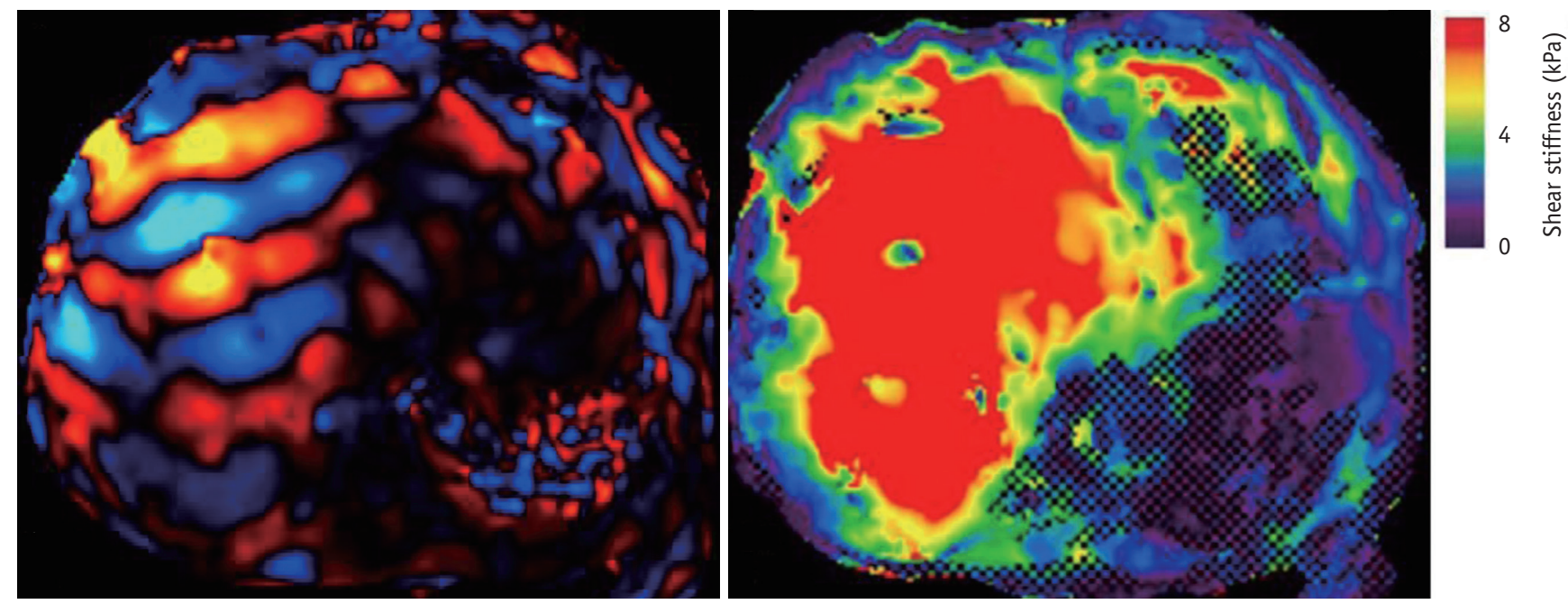

A

B
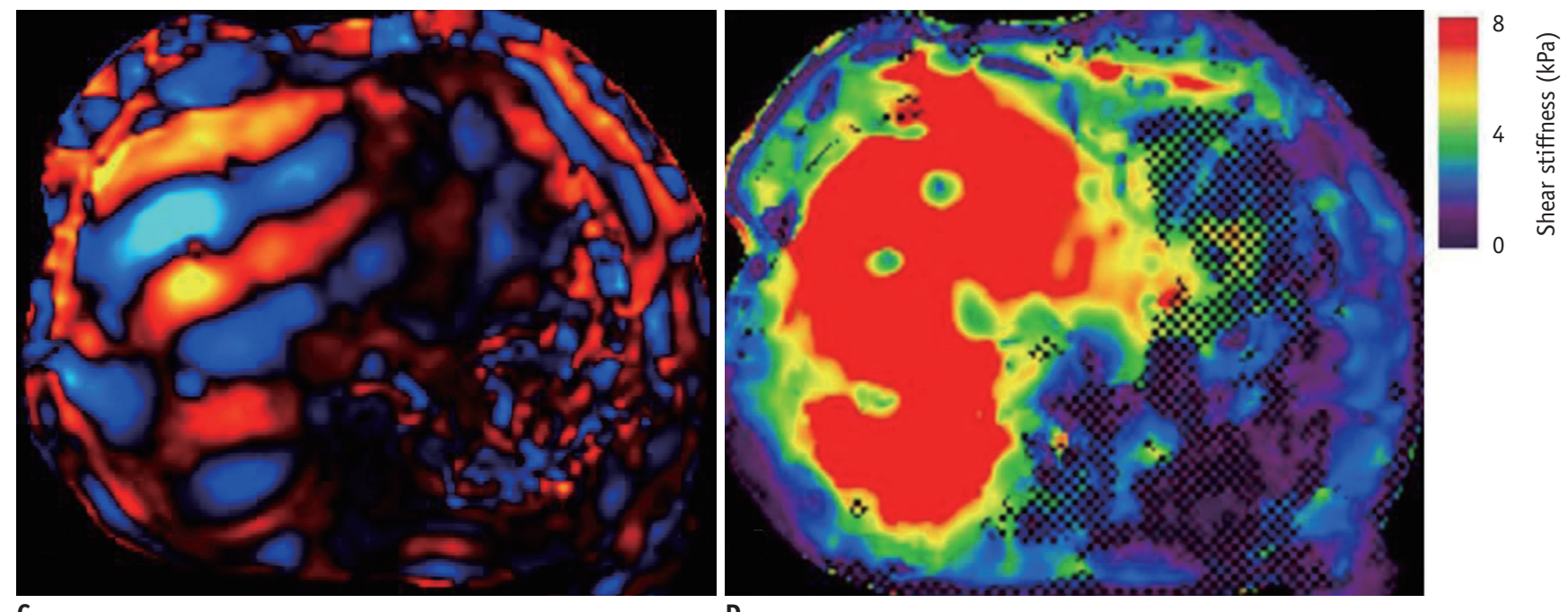

Fig. 2. MRE measurement of LS.

Two liver MRE scans were performed to assess reproducibility in patient with BCS. First (A, B) and second (C, D) MRE results are shown. A, C. Wave images. B, D. MREs. There were no significant differences between two elastograms. BCS $=$ Budd-Chiari syndrome, $L S=$ liver stiffness, MRE $=$ magnetic resonance elastography

noninvasive technique for detecting hepatic fibrosis, and LS values can be used to grade fibrosis (13-15). Lee et al. (16) reported good repeatability and reproducibility of the LS measurement using MRE. In their study, 94 patients underwent MRE for one of the following reasons: evaluation for hepatocellular carcinoma $(n=26)$, liver metastases $(n=$ $24)$, viral hepatitis, or liver cirrhosis $(n=8)$, routine followup for another malignancy $(n=32)$, and evaluation for other reasons $(n=4)$. BCS was not specifically mentioned in their study. Primary BCS is a rare disorder caused by thrombosis of the HV or IVC. Hepatic venous outflow obstruction results in congestion and ischemia that can eventually lead to atrophy and fibrosis in BCS (17). In addition, ascites and different types of intra- and extra- hepatic collateral circulations are frequently detected in BCS $(18,19)$. One study found that massive ascites was an independent factor associated with failure of liver MRE (20). The reliability of LS measurement in BCS was previously unknown. Our results indicate that MRE is a useful tool for evaluating LS in BCS patients with high repeatability and reproducibility.

Endovascular intervention has proved to be more effective than open surgery for the treatment of BCS. Specifically, in patients with membranous IVC occlusion, a single balloon dilation can achieve better results (21). Because endovascular intervention is both minimally invasive and effective, it has been the first choice for BCS treatment (21). The mainstays of BCS therapy include restoring HV outflow 


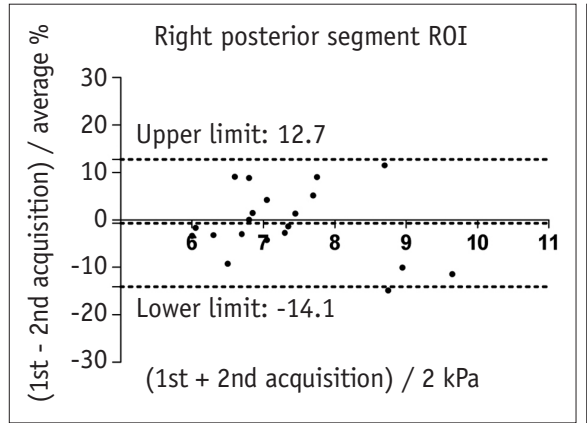

A

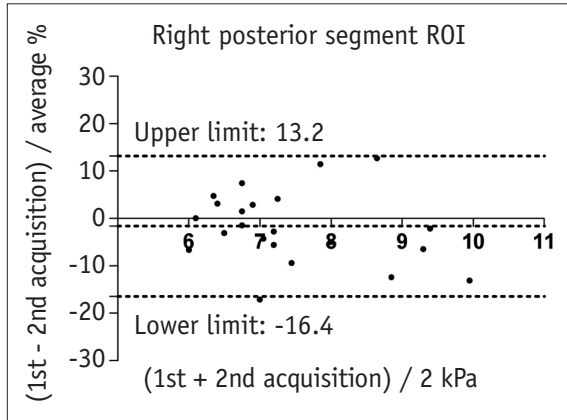

D
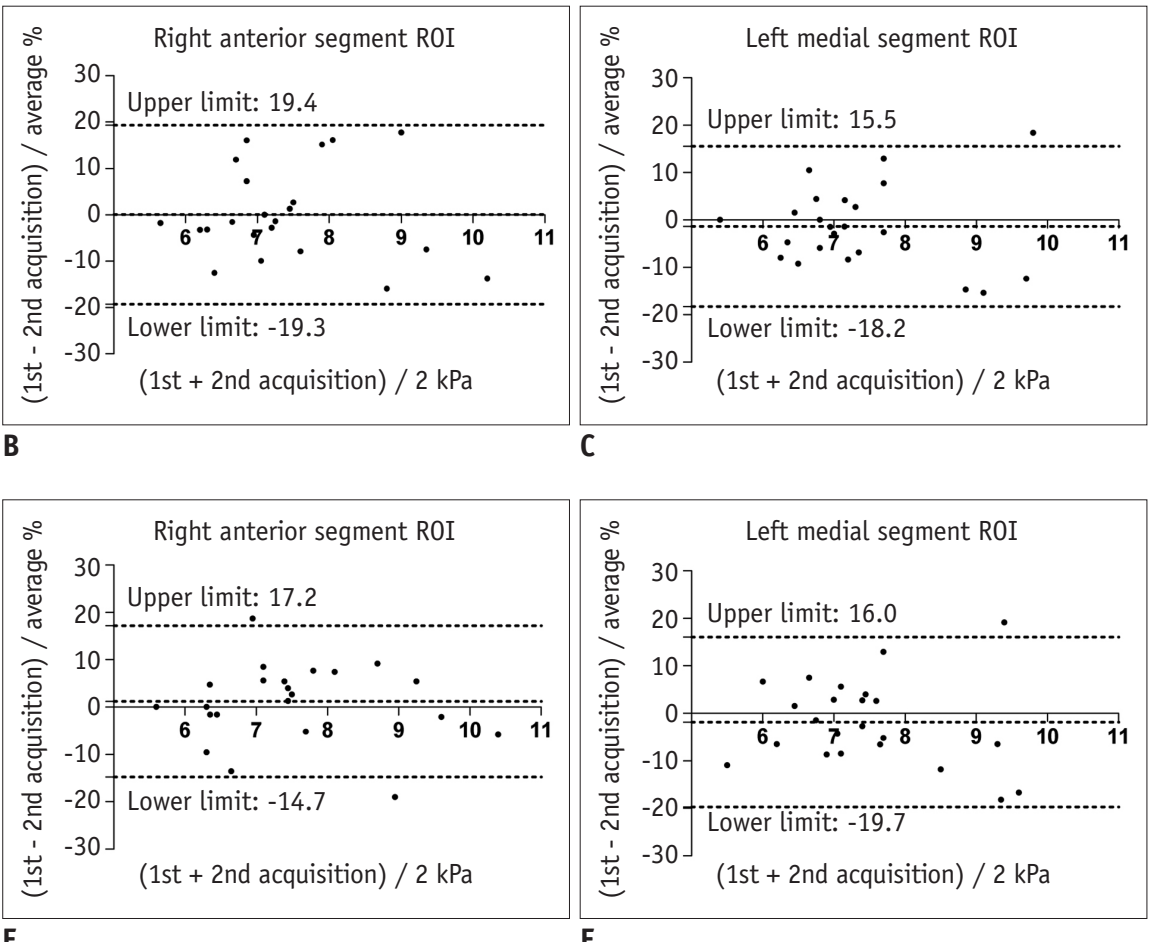

$\mathbf{F}$

Fig. 3. Bland-Altman analysis between two MRE scans for each reader (A-C, Reader 1; D-F, Reader 2) and for each measured segment. $X$-axes show means of measured LS values, and $Y$-axes show differences between LS values as percentage of their mean.

Table 2. ICC Comparison between Two Readers $(n=23)$

\begin{tabular}{ccc}
\hline ICC $(95 \%$ CI $)$ & First Acquisition & Second Acquisition \\
\hline Right posterior segment ROI & $0.847(0.639-0.935)$ & $0.914(0.797-0.964)$ \\
Right anterior segment ROI & $0.902(0.770-0.959)$ & $0.943(0.864-0.976)$ \\
Left medial segment ROI & $0.912(0.792-0.963)$ & $0.839(0.658-0.928)$ \\
\hline
\end{tabular}

Table 3. Distributions of LS Values Before and After Treatment $(n=15)$

\begin{tabular}{llll}
\hline \multicolumn{1}{c}{ Liver Segments } & \multicolumn{1}{c}{ LS $(\mathrm{kPa})$ Before } & LS (kPa) After & $P$ \\
\hline Right posterior segment ROI & $7.23 \pm 0.88(6.02-9.22)$ & $4.94 \pm 0.84(3.90-6.21)$ & 0.001 \\
Right anterior segment ROI & $7.30 \pm 1.06(5.62-10.31)$ & $4.77 \pm 0.85(3.81-6.43)$ & 0.001 \\
Left medial segment ROI & $7.22 \pm 0.87(5.95-9.65)$ & $4.87 \pm 0.72(3.86-6.10)$ & 0.001 \\
\hline
\end{tabular}

LS values are presented as mean \pm standard deviation (95\% CI).

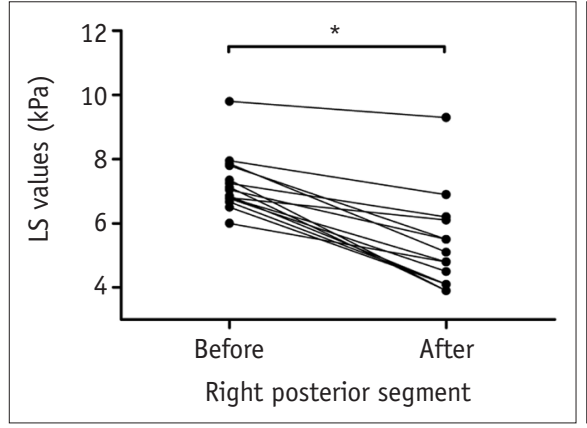

A

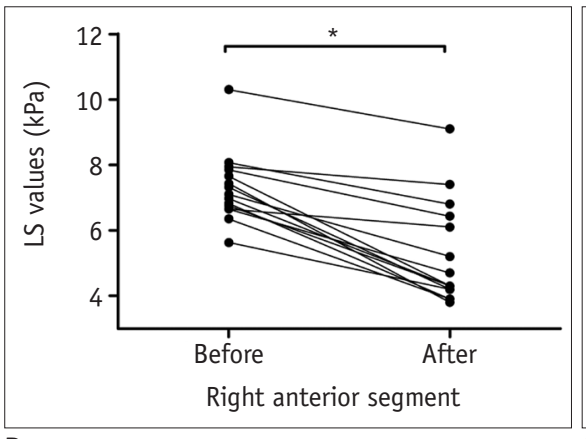

B

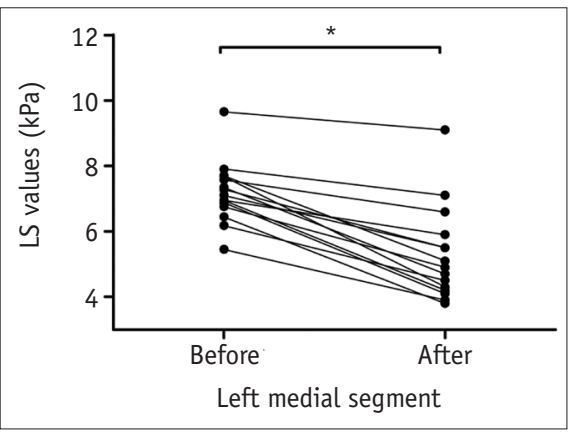

C

Fig. 4. LS values decreased significantly after intervention in all three segments.

A. Right posterior segment. B. Right anterior segment. C. Left medial segment. ${ }^{*} p<0.05$. 


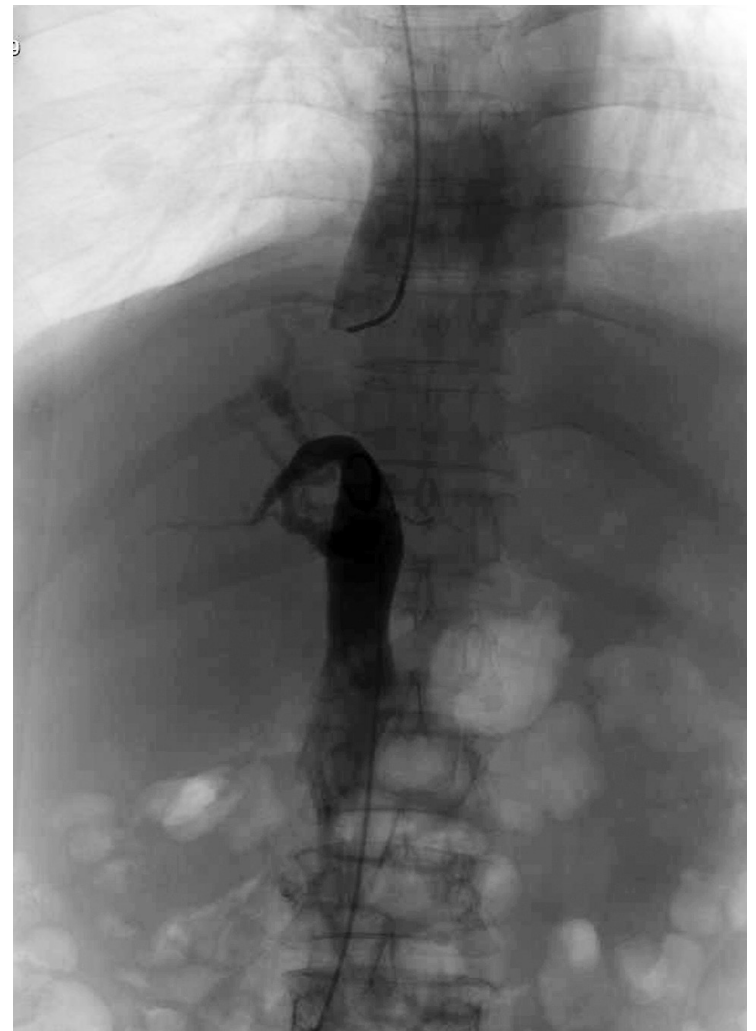

A
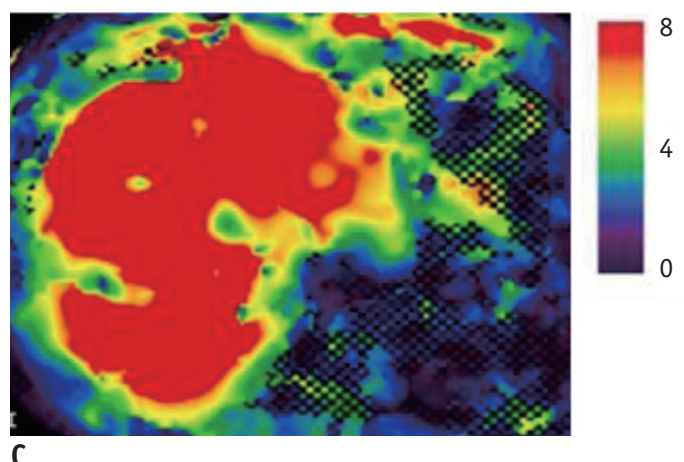

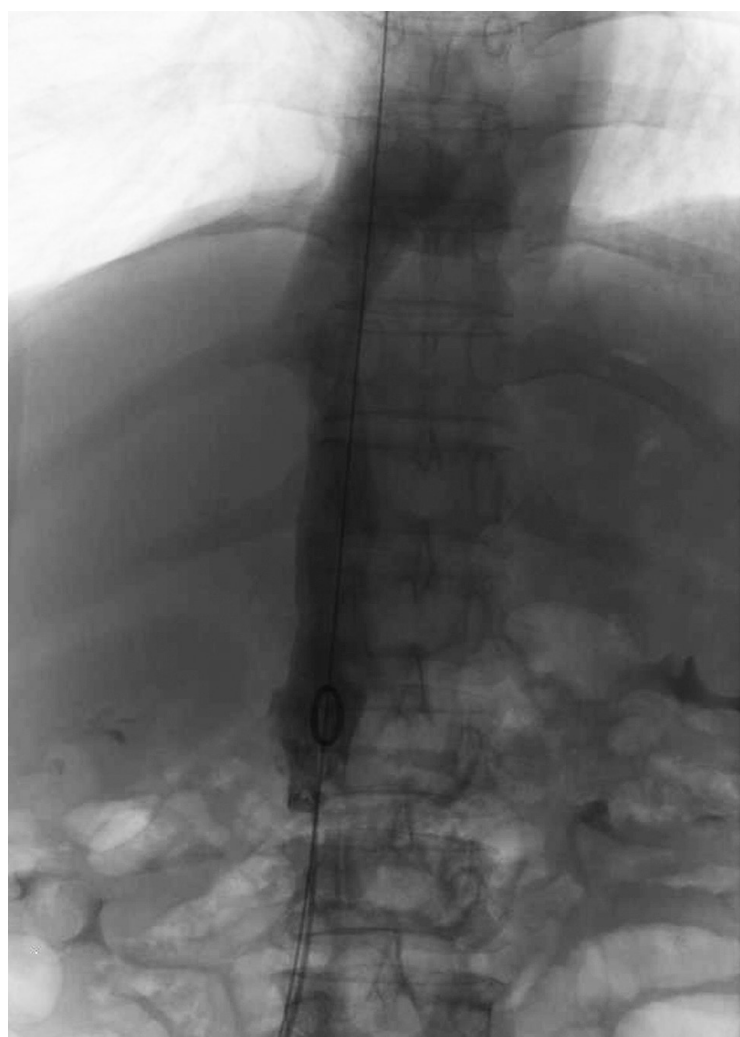

B

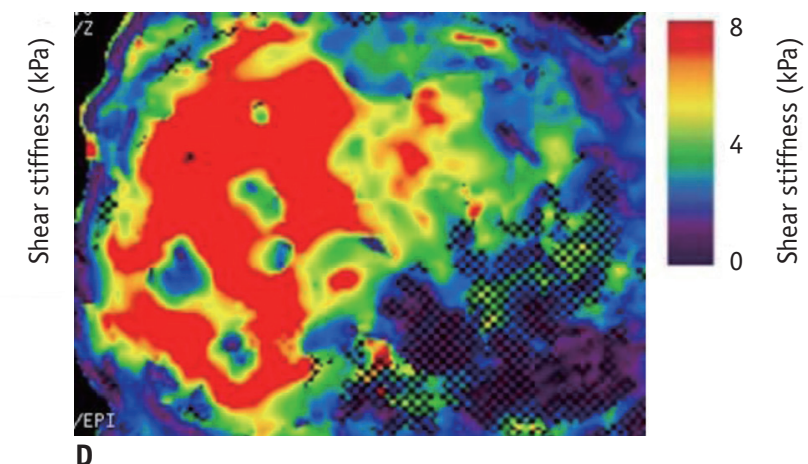

Fig. 5. Changes in digital subtraction angiography (A. before, B. after) and MRE (C. before, D. after) in patient with BCS who underwent interventional treatment. A. IVC obstruction. B. Free blood flow in IVC after balloon dilation. C, D. Post-procedural LS values (6.17 $\mathrm{kPa}$ ) were lower than pre-procedural measurements $(7.53 \mathrm{kPa}) . \mathrm{IVC}=$ Inferior vena cava

tract patency and reducing hepatic congestion. Decreased ascites volume, resolution of hepatomegaly, and significant reduction of the stenotic HV/IVC pressure gradient after intravascular surgery may lead to decreased liver congestion (22). In the present study, the LS values of 15 patients who had undergone balloon dilation decreased after the procedure, probably partially due to an immediate reduction in liver congestion. This finding is consistent with the observations of Mukund et al. (7) who used TE to assess changes in hepatic congestion following endovascular intervention in $\mathrm{BCS}$.
We also found a correlation between changes in LS and pressure gradient before and after treatment, which might indirectly confirm the effect of liver congestion on LS.

Clinical manifestations were also significantly improved one month after balloon dilation therapy. Based on our findings and previous studies, we hypothesize that two components affect $L S$ in BCS patients: liver congestion and fibrosis. Therefore, we propose that MRE can be used for follow-up monitoring of these patients after interventional treatment.

Our study has several limitations. First, due to its invasiveness, we did not perform liver biopsies, which 
Table 4. Comparison of Clinical Characteristics Before and After Treatment $(n=15)$

\begin{tabular}{|c|c|c|c|}
\hline Variables & Before & After & $P$ \\
\hline \multicolumn{4}{|l|}{ Biochemical indicators } \\
\hline ALB, $g / L$ & $31.3 \pm 5.5$ & $37.0 \pm 4.8$ & $<0.001$ \\
\hline ALT, U/L & $38.4 \pm 17.5$ & $34.7 \pm 11.3$ & 0.291 \\
\hline AST, U/L & $37.8 \pm 15.6$ & $32.5 \pm 9.1$ & 0.126 \\
\hline PT, s & $14.0 \pm 1.7$ & $13.1 \pm 1.1$ & 0.009 \\
\hline TBIL, $\mu \mathrm{mol} / \mathrm{L}$ & $30.1 \pm 10.1$ & $26.5 \pm 7.3$ & 0.005 \\
\hline \multicolumn{4}{|l|}{ Clinical presentations } \\
\hline Weakness, n (\%) & $11(73.3)$ & $1(6.7)$ & $<0.001$ \\
\hline $\begin{array}{l}\text { Thoracoabdominal varices, } \\
\mathrm{n}(\%)\end{array}$ & $13(86.7)$ & $3(20.0)$ & 0.001 \\
\hline Ascites, n (\%) & $6(40.0)$ & $0(0)$ & 0.017 \\
\hline $\begin{array}{l}\text { Lower-extremity edema, } \\
\mathrm{n}(\%)\end{array}$ & $12(80.0)$ & $2(13.3)$ & 0.001 \\
\hline Child-Pugh score & $6.2 \pm 1.3$ & $5.9 \pm 1.1$ & 0.019 \\
\hline Pressure gradient, $\mathrm{mmHg}$ & $19.9 \pm 5.2$ & $10.8 \pm 2.4$ & $<0.001$ \\
\hline
\end{tabular}

Values are mean \pm standard deviation unless otherwise indicated. $\mathrm{ALB}=$ albumin, $\mathrm{ALT}=$ alanine aminotransferase, $\mathrm{AST}=$ aspartate aminotransferase, $\mathrm{PT}=$ prothrombin time, $\mathrm{TBIL}=$ total bilirubin

might directly confirm the effect of liver congestion on LS. Second, segmental intrahepatic variations might occur in patients with BCS, which might affect precise ROI positioning (7). We measured only the largest area of the liver, and not the left lateral segment, to avoid possible diaphragmatic and cardiac motion artifacts. Third, although inter-examination and inter-reader repeatability were assessed, we did not assess intra-reader repeatability. Furthermore, because we evaluated the short-term reproducibility of LS measurements, our results might overestimate reproducibility. Fourth, due to the variable degree of stenosis of the HV or IVC in each patient, certain individual differences were observed during the evaluation of the effectiveness of its interventional treatment. Moreover, considering the possibility of the radiofrequency heating the stent and the imaging artifacts due to stent susceptibility, we only included patients treated with balloon dilation. The assessment of patients treated with stents should be pursued in future studies.

In conclusion, two examinations in BCS patients showed that MRE-based LS measurements are repeatable. MRE can be used to monitor these patients after interventional treatment.

\section{Conflicts of Interest}

The authors have no potential conflicts of interest to disclose.
Acknowledgments

Authors gratitude to Mr. Weiqiang Dou (GE Healthcare, MR Research China) for optimization of MRI scanning parameters.

\author{
ORCID iDs \\ Kai Xu \\ https://orcid.org/0000-0002-1712-4806 \\ Peng Xu \\ https://orcid.org/0000-0002-3321-9602 \\ Lulu Lyu \\ https://orcid.org/0000-0002-4690-4158 \\ Haitao Ge \\ https://orcid.org/0000-0002-1474-4583 \\ Muhammad Umair Sami \\ https://orcid.org/0000-0001-6604-5584 \\ Panpan Liu \\ https://orcid.org/0000-0003-4005-660X \\ Chunfeng Hu \\ https://orcid.org/0000-0001-6804-7401
}

\section{REFERENCES}

1. Plessier A, Rautou PE, Valla DC. Management of hepatic vascular diseases. J Hepatol 2012;1:S25-S38

2. Copelan A, Remer EM, Sands M, Nghiem H, Kapoor B. Diagnosis and management of Budd Chiari syndrome: an update. Cardiovasc Intervent Radiol 2015;38:1-12

3. Tang A, Cloutier G, Szeverenyi NM, Sirlin CB. Ultrasound elastography and MR elastography for assessing liver fibrosis: part 2, diagnostic performance, confounders, and future directions. AJR Am J Roentgenol 2015;205:33-40

4. Han KH, Yoon KT. New diagnostic method for liver fibrosis and cirrhosis. Intervirology 2008;51 Suppl 1:11-16

5. Srinivasa Babu A, Wells ML, Teytelboym OM, Mackey JE, Miller $\mathrm{FH}$, Yeh BM, et al. Elastography in chronic liver disease: modalities, techniques, limitations, and future directions. Radiographics 2016;36:1987-2006

6. Yoon JH, Lee JM, Woo HS, Yu MH, Joo I, Lee ES, et al. Staging of hepatic fibrosis: comparison of magnetic resonance elastography and shear wave elastography in the same individuals. Korean J Radiol 2013;14:202-212

7. Mukund A, Pargewar SS, Desai SN, Rajesh S, Sarin SK. Changes in liver congestion in patients with Budd-Chiari Syndrome following endovascular interventions: assessment with transient elastography. J Vasc Interv Radiol 2017;28:683-687

8. Huwart L, Sempoux C, Vicaut E, Salameh N, Annet L, Danse E, et al. Magnetic resonance elastography for the noninvasive staging of liver fibrosis. Gastroenterology 2008;135:32-40

9. Huwart L, Sempoux C, Salameh N, Jamart J, Annet L, Sinkus 
$R$, et al. Liver fibrosis: noninvasive assessment with $M R$ elastography versus aspartate aminotransferase-to-platelet ratio index. Radiology 2007;245:458-466

10. Trout AT, Sheridan RM, Serai SD, Xanthakos SA, Su W, Zhang $B$, et al. Diagnostic performance of MR elastography for liver fibrosis in children and young adults with a spectrum of liver diseases. Radiology 2018;287:824-832

11. Lee JE, Lee JM, Lee KB, Yoon JH, Shin CI, Han JK, et al. Noninvasive assessment of hepatic fibrosis in patients with chronic hepatitis $B$ viral infection using magnetic resonance elastography. Korean J Radiol 2014;15:210-217

12. Yoshimitsu K, Mitsufuji T, Shinagawa Y, Fujimitsu R, Morita A, Urakawa $\mathrm{H}$, et al. MR elastography of the liver at 3.0 $T$ in diagnosing liver fibrosis grades; preliminary clinical experience. Eur Radiol 2016;26:656-663

13. Rouvière 0 , Yin $M$, Dresner MA, Rossman PJ, Burgart LJ, Fidler $\mathrm{JL}$, et al. MR elastography of the liver: preliminary results. Radiology 2006;240:440-448

14. Venkatesh SK, Wang G, Lim SG, Wee A. Magnetic resonance elastography for the detection and staging of liver fibrosis in chronic hepatitis B. Eur Radiol 2014;24:70-78

15. Tan $\mathrm{CH}$, Venkatesh SK. Magnetic resonance elastography and other magnetic resonance imaging techniques in chronic liver disease: current status and future directions. Gut Liver 2016;10:672-686

16. Lee YJ, Lee JM, Lee JE, Lee KB, Lee ES, Yoon JH, et al. MR elastography for noninvasive assessment of hepatic fibrosis: reproducibility of the examination and reproducibility and repeatability of the liver stiffness value measurement. J Magn Reson Imaging 2014;39:326-331

17. Noone TC, Semelka RC, Siegelman ES, Balci NC, Hussain SM, Kim PN, et al. Budd-Chiari syndrome: spectrum of appearances of acute, subacute, and chronic disease with magnetic resonance imaging. J Magn Reson Imaging 2000;11:44-50

18. Cai SF, Gai YH, Liu QW. Computed tomography angiography manifestations of collateral circulations in Budd-Chiari syndrome. Exp Ther Med 2015;9:399-404

19. Cho OK, Koo JH, Kim YS, Rhim HC, Koh BH, Seo HS. Collateral pathways in Budd-Chiari syndrome: CT and venographic correlation. AJR Am J Roentgenol 1996;167:1163-1167

20. Wagner M, Corcuera-Solano I, Lo G, Esses S, Liao J, Besa C, et al. Technical failure of MR elastography examinations of the liver: experience from a large single-center study. Radiology 2017;284:401-412

21. Huang $Q$, Shen B, Zhang $Q, X u H, Z u$ M, Gu Y, et al. Comparison of long-term outcomes of endovascular management for membranous and segmental inferior vena cava obstruction in patients with primary Budd-Chiari Syndrome. Circ Cardiovasc Interv 2016;9:e003104

22. Lee BB, Villavicencio L, Kim YW, Do YS, Koh KC, Lim HK, et al. Primary Budd-Chiari syndrome: outcome of endovascular management for suprahepatic venous obstruction. J Vasc Surg 2006;43:101-108 